\title{
Genetic Study in a Case of Birt-Hogg-Dubé Syndrome
}

\author{
Geon Park, M.D. ${ }^{1}$, Hae Ryun Kim, M.D., Chan Ho Na, M.D., Kyu Chul Choi, M.D., \\ Bong Seok Shin, M.D. \\ Departments of Dermatology, ${ }^{1}$ Laboratory Medicine, School of Medicine, Chosun University, Gwangju, Korea
}

Birt-Hogg-Dubé syndrome (BHDS) is an autosomal dominantly inherited disorder characterized by multiple trichodiscomas, fibrofolliculomas, and acrocordons. There is also an increased risk of developing renal neoplasms and lung cysts/spontaneous pneumothorax. We present a 43-year-old man with multiple, 2 $4 \mathrm{~mm}$ sized, dome-shaped, and skin-colored papules on his cheek and neck. On the basis of clinical finding and histopathologic examination on the cheek lesion, it was diagnosed as multiple trichodiscomas. Subsequently, molecular analysis revealed a mutation in the folliculin gene. We report a rare case of BHDS with a proved gene mutation. (Ann Dermatol 23(S2) S188 S192, 2011)

\section{-Keywords-}

Birt-Hogg-Dubé syndrome, Fibrofolliculomas, Trichodiscomas

\section{INTRODUCTION}

Birt-Hogg-Dubé syndrome ${ }^{1}$ (BHDS) is a rare autosomal dominant disease characterized by a triad of benign skin tumors consisting of multiple fibrofolliculoma, trichodiscoma, and acrochordon on the face, neck, and upper trunk. The lesions clinically appear as multiple, $2 \sim 4 \mathrm{~mm}$, white to skin-colored, and dome shaped papules, affecting the face and upper trunk. In further studies, an association between BHDS and renal neoplasm and lung cyst/

Received March 24, 2010, Revised Febrary 18, 2011, Accepted for publication March 15, 2011

Corresponding author: Bong Seok Shin, M.D., Department of Dermatology, School of Medicine, Chosun University, 588 Seoseok-dong, Dong-gu, Gwangju 501-717, Korea. Tel: 82-62-220-3130, Fax: 82-62222-3215, E-mail: derm75@hanmail.net

This is an Open Access article distributed under the terms of the Creative Commons Attribution Non-Commercial License (http:// creativecommons.org/licenses/by-nc/3.0) which permits unrestricted non-commercial use, distribution, and reproduction in any medium, provided the original work is properly cited. spontaneous pneumothorax was also suggested ${ }^{2,3}$. BHDS is caused by a mutation in the gene folliculin (FLCN) which is located on chromosome $17 \mathrm{p} 11.2^{4}$. We report a patient with BHDS for whom molecular analysis revealed a mutation in folliculin gene.

\section{CASE REPORT}

A 43-year-old man presented with a 15-year history of intermittent pruritic, multiple, skin-colored papules on the face and neck. The lesions developed on the face at first, and then slowly progressed to the neck, covering a 15-year period. Physical examination revealed multiple firm, skin-colored, 2 $4 \mathrm{~mm}$ sized, papular lesions distributed on the face and neck area (Fig. 1). Except for the cutaneous findings, the patient was otherwise well and had no past history of kidney disease, pneumothorax, or other tumors. The result of the routine laboratory studies and chest x-ray were either normal or negative. His father died after suffering from colon cancer and his younger brother was ill with a pneumothorax. He also stated that his daughters had similar symptoms to his skin lesions.

A biopsy of one of the facial papules was performed, and the lesion was reminiscent of a fibrofolliculoma by concentric fibrous tissue around follicular epithelium with thin and anastomosing bands separating from adjacent fibrovascular proliferation (Fig. 2). Meanwhile, another section of the same sample showed a relatively welldefined fibrovascular lesion with vascular proliferation and hair follicle at the margin of the lesion, suggesting trichodiscoma (Fig. 3). We studied the molecular genetic status of the FLCN gene after informed consent from the patient. We performed direct amplification of all exons (exon 1-14) of FLCN using previously reported primer sets and PCR conditions ${ }^{5}$. Direct amplification of FLCN from EDTA-treated whole blood was performed using AnyDirectMaxTM Taq REDMix (BioQuest, Seoul, Korea) ${ }^{6}$. After gel purification of direct amplicon using a Gel 

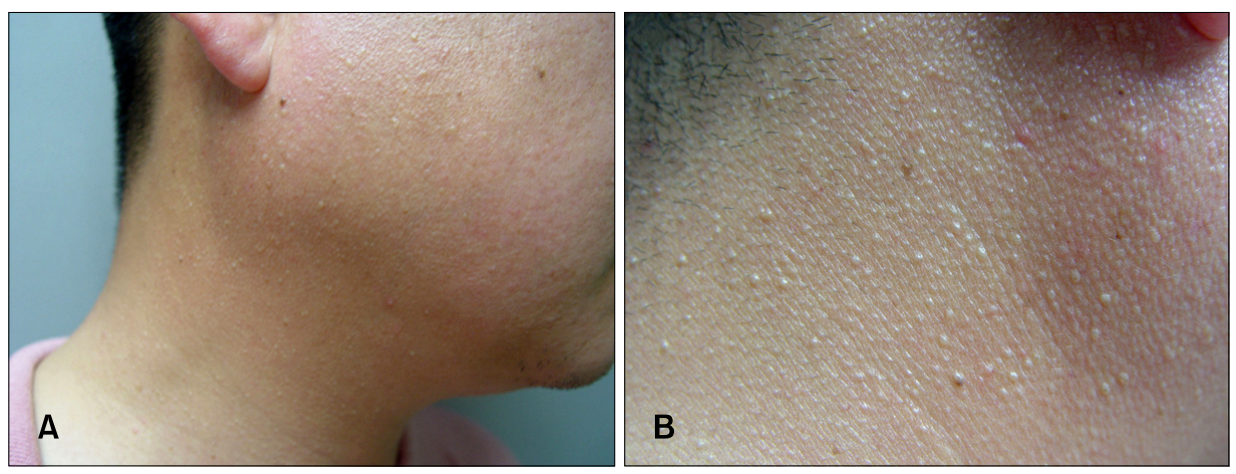

Fig. 1. (A) Multiple firm, skincolored, 2 4 mm sized, papular lesions distributed on the face and neck area of the patient. (B) The magnified clinical appearance of the papules on the lateral side of the right neck.
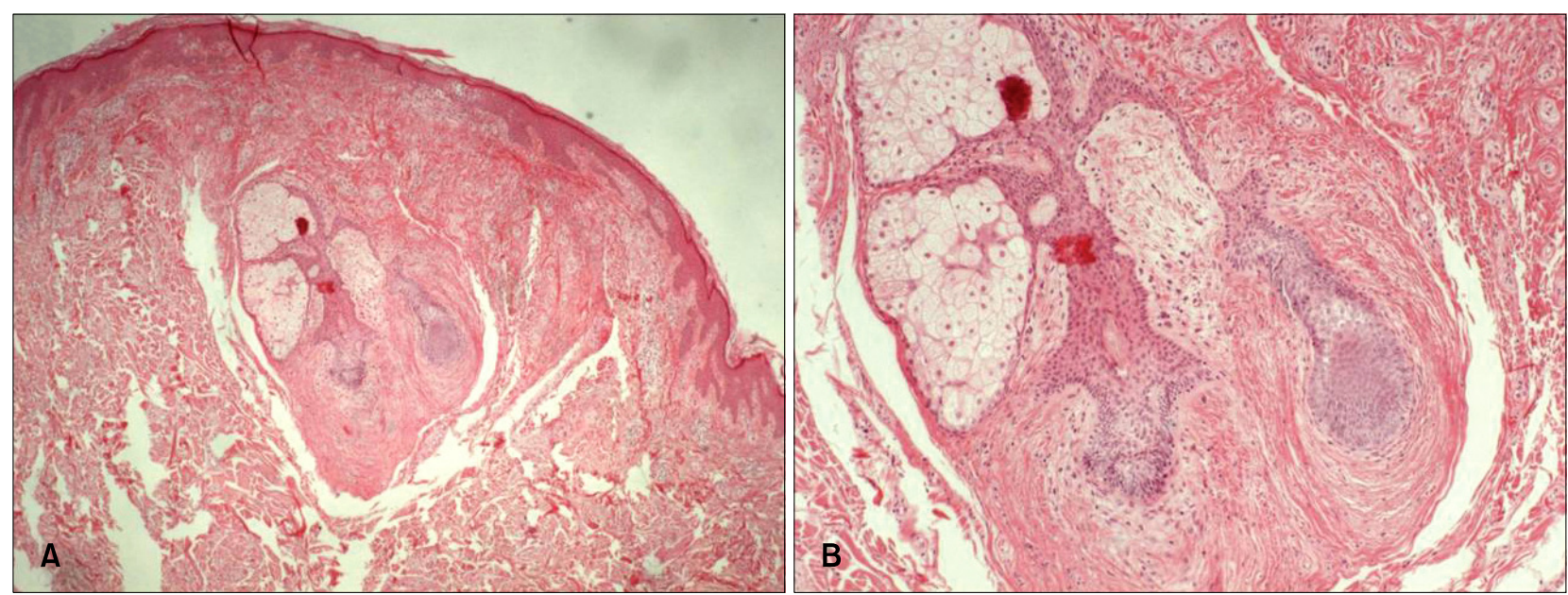

Fig. 2. (A) Relatively well-defined fibrovascular lesion in the superficial dermis (H\&E, original magnification $\times 40)$. (B) Higher magnification of central area. Concentric fibrous tissue around follicular epithelium with thin and anastomosing bands separating from adjacent fibrovascular proliferation $(\mathrm{H} \& \mathrm{E}$, original magnification $\times 200)$.
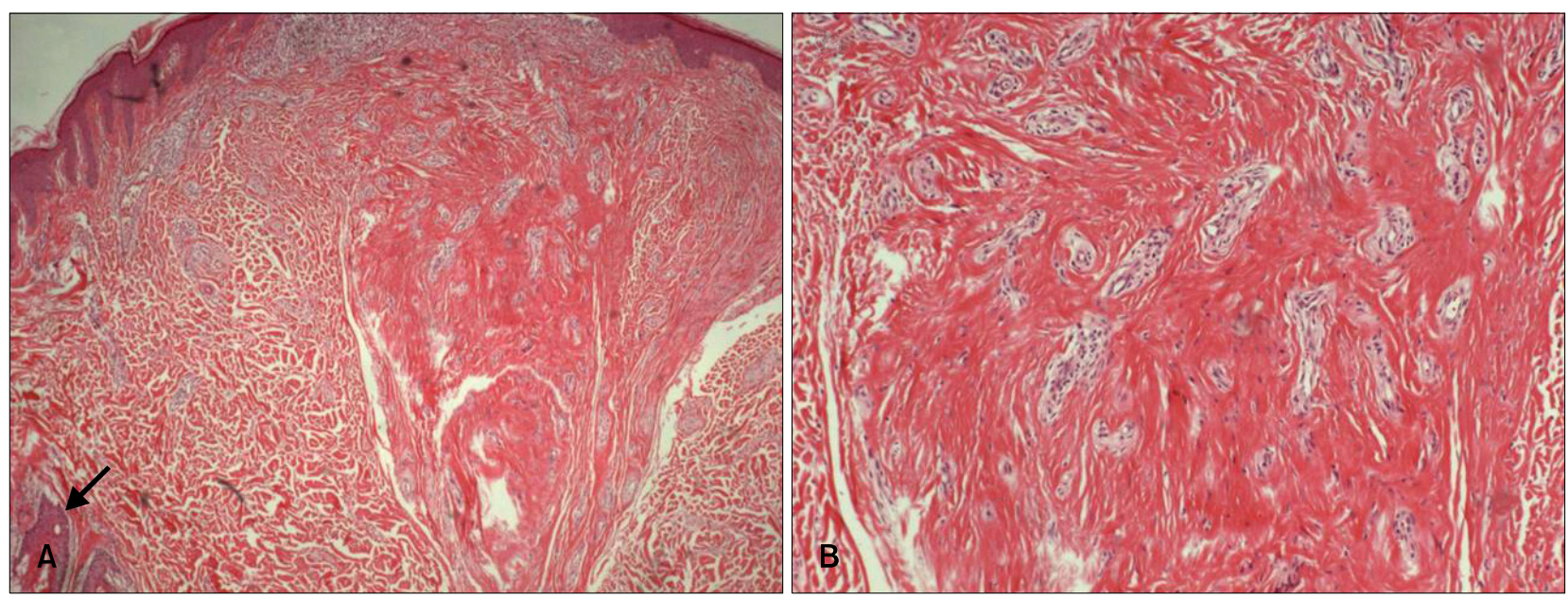

Fig. 3. (A) Fibrovascular lesion with vascular proliferation and hair follicle (arrow) at the margin of the lesion (H\&E, original magnification $\times 40$ ). (B) Higher magnification of fibrovascular lesion. Vascular proliferation in coarse connective tissue (H\&E, original magnification $\times 200)$.

Purification Kit (Solgent, Daejeon, Korea), direct sequencing was performed by ABI 3730XL Sequencer (Applied Biosystems, Foster, CA, USA). Sequencing analysis revealed a heterozygotic c.1285dupC mutation (accession No. NM_144997) in the FLCN gene exon 11 (Fig. 4). This mutation was the same as the previously described 
A
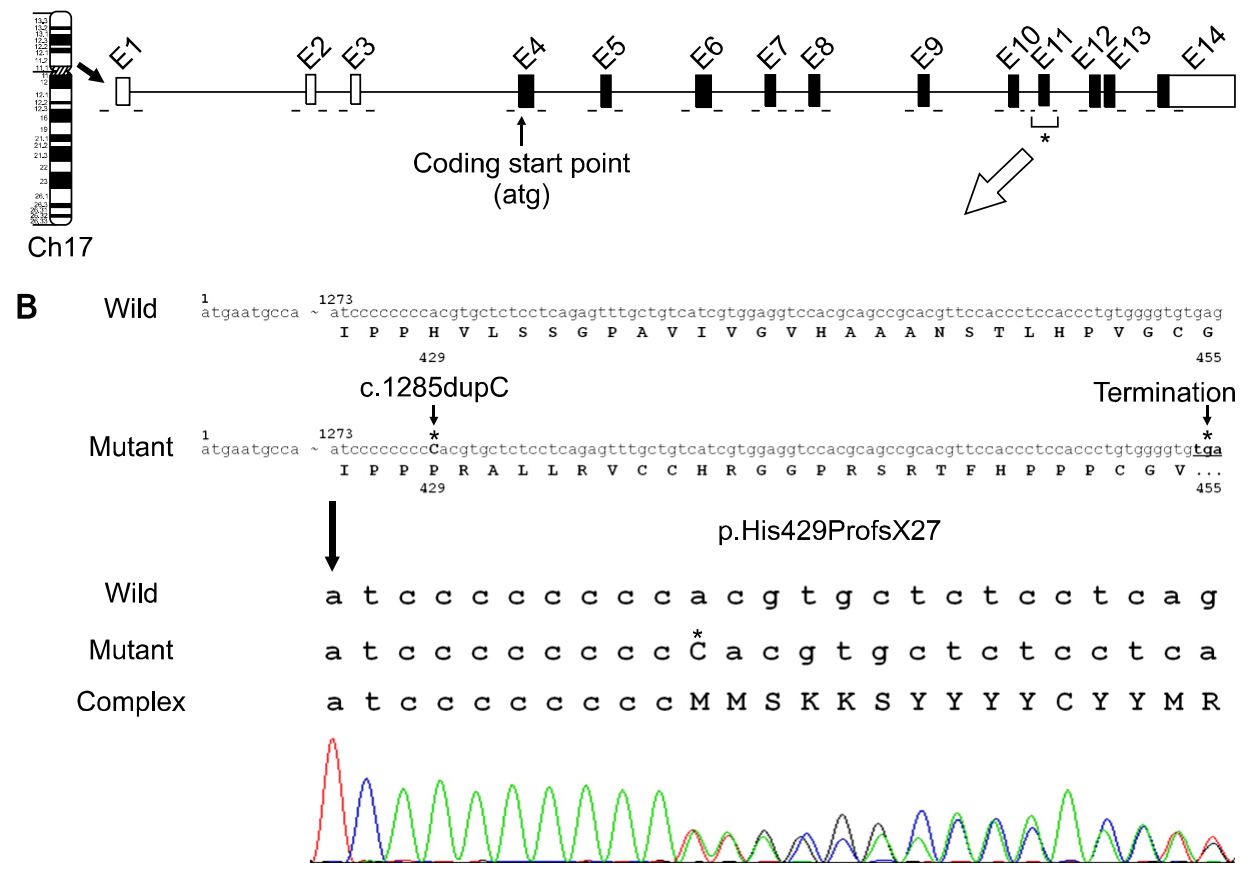

Fig. 4. (A) Illustrated FLCN map and $(B)$ the result of sequence analysis of FLCN gene, showing duplication of a cytosine in exon 11 (c.1285 dupC).

1733ins C mutation. This mutation results in producing the truncated protein folliculin, which is caused by a frameshift of the amino acid sequence in the FLCN gene product (Fig. 4). Based on this, we were able to diagnose this patient as BHDS, with support from his clinical and histological findings, family history, and gene mutation revealed by sequencing analysis at genomic DNA level.

\section{DISCUSSION}

BHDS is a rare autosomal dominant disorder that was first described in 1977 by Birt, Hogg, and Dubé ${ }^{1}$. Cutaneous lesions characterized by small, firm, dome shaped, white or skin-colored papular skin lesions distributed over the scalp, forehead, face, and neck were diagnosed as fibrofolliculoma and trichodiscoma, which are difficult to distinguish clinically. With additional noted acrochordon ${ }^{7}$, this triad became known as BHDS. Also, recent reports revealed that affected patients are associated with lung cysts, recurrent spontaneous pneumothorax ${ }^{3,8}$, and renal neoplasms ${ }^{9}$, but we failed to detect any visceral lesions in our patient. In 2002, Zbar et al. ${ }^{2}$ reported that the risk of BHDS developing was about 9 and 32 times more likely to develop with renal tumor and spontaneous pneumothorax compared to unaffected persons, respectively. However, they found no increase in the risk for colorectal polyps and cancer, although some patients also may suffer from these. The cutaneous lesions usually appear in the third or fourth decades ${ }^{10,11}$. Clinical diagnosis of BHDS is usually defined when over 10 skin lesions are clinically compatible with fibrofolliculoma and at least 1 lesion histologically compatible with fibrofolliculoma ${ }^{5,12}$. Although fibrofolliculoma and trichodiscoma in BHDS are indistinguishable clinically ${ }^{13}$, some would distinguish these diseases histologically ${ }^{7}$. Fibrofolliculoma exhibits a central distorted hair follicle that is surrounded by a mantle of basophilic fibrous stroma ${ }^{1,14}$. Dilation or distortion of the hair follicle and anastomosing septa of follicular epithelium classically distinguish fibrofolliculoma from trichodiscoma $^{15}$. On the other hand, trichodiscoma can be seen in the dermis as an area of fine fibrillary connective tissue containing ectatic blood vessels. Epithelial hyperplasia resembling follicular structures as seen in fibrofolliculoma and hair follicles at the margin of the lesion are often seen. Thus, some authors maintained that fibrofolliculoma and trichodiscoma are separate entities based on the histological criteria originally outlined by Pinkus et al. in $1974^{16}$. However, many recent authors considered that fibrofolliculoma and trichodiscoma in patients with suspected BHDS were actually variations of the same disorder ${ }^{17}$. Steffen and Ackerman ${ }^{18}$ argued that fibrofolliculoma and trichodiscoma are a single pathologic condition. They explained that both diseases share the same epithelial and mesenchymal components, differing only in the predominance of the epithelial component in fibrofolliculoma and of the connective tissue in trichodiscoma. In addition, they offered that characteristics of both can be found on the same biopsy, which confounds 
the possibility for definitive diagnosis if care is not taken to examine the biopsy specimen thoroughly. Collins et al. ${ }^{19}$ also found that fibrofolliculoma and trichodiscoma that occur with BHDS show microscopically contiguous histomorphologic features as compared with those that occur sporadically. They add that, despite subtle histomorphologic differences, trichodiscoma and fibrofolliculoma are immunophenotypically similar, and are thus likely derived from a similar histogenic precursor. Likewise, we believe that both diseases are part of a spectrum of conditions, because the serial sectioning of our patient's specimen showed each histopathologic finding of fibrofolliculoma and trichodiscoma. Histopathologic findings showed concentric fibrous tissue around follicular epithelium with thin and anastomosing bands separated from adjacent fibrovascular proliferation, and fibrovascular lesion with vascular proliferation and hair follicle at the margin of the lesion, respectively.

Though the incidence of BHDS is unknown, there is speculation that it is underdiagnosed $d^{7,20}$.

The responsible gene has been mapped to chromosome $17 \mathrm{p} 11.2$, recently identified as the FLCN gene encoding genetic information of folliculin protein ${ }^{10,21}$. FLCN is composed of a total 14 exons and 11 coding exons (Fig. 4). The function of folliculin is still unknown, although it is speculated to be a tumor suppressor gene.

A germline mutation in the tumor suppressor BHDS gene is underlying pathology. Several BHDS germline mutations have been identified in the translated exons 4-14 except exon 8 and 10. The most common mutations are c.1285dupC and c.1285delC located in exon 11, representing about $50 \%$ of reported mutations ${ }^{22}$. In particular, the c.1285dupC mutation is a hot spot in Asian BHDS patients $^{21}$. However, novel mutations have been detected continuously ${ }^{4,23,24}$.

The treatment of BHDS includes screening and management of kidney, lung, and colon findings. For cosmetic needs of the skin lesions, laser therapy or shave excision can be made available.

This case emphasizes that a dermatologist need to be aware of BHDS when evaluating patients with multiple flesh-colored papules on the face, neck, and upper trunk. If the skin findings of BHDS are misdiagnosed as simply acrochordon, we may fail to have any chance at detecting early stages of associated cancers. Therefore, if BHDS is suspected, we believe that the patient and their family members should undergo a medical investigation of the kidney, lung, and colon and a genetic testing for closed follow up to genetic carrier.

We report a patient with BHDS who presented multiple papules on the face and neck and revealed a mutation in the folliculin gene.

\section{REFERENCES}

1. Birt AR, Hogg GR, Dubé WJ. Hereditary multiple fibrofolliculomas with trichodiscomas and acrochordons. Arch Dermatol 1977;113:1674-1677.

2. Zbar B, Alvord WG, Glenn G, Turner M, Pavlovich CP, Schmidt $L$, et al. Risk of renal and colonic neoplasms and spontaneous pneumothorax in the Birt-Hogg-Dubé syndrome. Cancer Epidemiol Biomarkers Prev 2002;11:393400.

3. Toro JR, Glenn G, Duray P, Darling T, Weirich G, Zbar B, et al. Birt-Hogg-Dubé syndrome: a novel marker of kidney neoplasia. Arch Dermatol 1999;135:1195-1202.

4. Kim EH, Jeong SY, Kim HJ, Kim YC. A case of Birt-HoggDubé syndrome. J Korean Med Sci 2008;23:332-335.

5. Nickerson ML, Warren MB, Toro JR, Matrosova V, Glenn G, Turner ML, et al. Mutations in a novel gene lead to kidney tumors, lung wall defects, and benign tumors of the hair follicle in patients with the Birt-Hogg-Dubé syndrome. Cancer Cell 2002;2:157-164.

6. Yang YG, Kim JY, Song YH, Kim DS. A novel buffer system, AnyDirect, can improve polymerase chain reaction from whole blood without DNA isolation. Clin Chim Acta 2007;380:112-117.

7. Vincent A, Farley M, Chan E, James WD. Birt-Hogg- Dubé syndrome: a review of the literature and the differential diagnosis of firm facial papules. J Am Acad Dermatol 2003; 49:698-705.

8. Chung JY, Ramos-Caro FA, Beers B, Ford MJ, Flowers F. Multiple lipomas, angiolipomas, and parathyroid adenomas in a patient with Birt-Hogg-Dube syndrome. Int J Dermatol 1996;35:365-367.

9. Roth JS, Rabinowitz AD, Benson M, Grossman ME. Bilateral renal cell carcinoma in the Birt-Hogg-Dubé syndrome. J Am Acad Dermatol 1993;29:1055-1056.

10. Misago N, Joh K, Yatsuki H, Soejima H, Narisawa Y. A BHD germline mutation identified in an Asian family with BirtHogg-Dubé syndrome. Acta Derm Venereol 2008;88:423425.

11. Welsch MJ, Krunic A, Medenica MM. Birt-Hogg-Dubé syndrome. Int J Dermatol 2005;44:668-673.

12. Schmidt LS, Nickerson ML, Warren MB, Glenn GM, Toro JR, Merino MJ, et al. Germline BHD-mutation spectrum and phenotype analysis of a large cohort of families with Birt-Hogg-Dubé syndrome. Am J Hum Genet 2005;76: 1023-1033.

13. Lee DA, Grossman ME, Schneiderman P, Celebi JT. Genetics of skin appendage neoplasms and related syndromes. J Med Genet 2005;42:811-819.

14. Weintraub R, Pinkus H. Multiple fibrofolliculomas (BirtHogg-Dubé) associated with a large connective tissue nevus. J Cutan Pathol 1977;4:289-299.

15. Elder DE. Lever's histopathology of the skin. 10th ed. Philadelphia: Lippincott Williams \& Wilkins, 2009:856-857.

16. Pinkus $\mathrm{H}$, Coskey R, Burgess GH. Trichodiscoma. A benign 
tumor related to haarscheibe (hair disk). J Invest Dermatol 1974;63:212-218.

17. Schulz T, Hartschuh W. Birt-Hogg-Dubé syndrome and Hornstein-Knickenberg syndrome are the same. Different sectioning technique as the cause of different histology. J Cutan Pathol 1999;26:55-61.

18. Steffen C, Ackerman AB. Neoplasms with sebaceous differentiation. Philadelphia: Lea \& Febiger, 1994:205-237.

19. Collins GL, Somach S, Morgan MB. Histomorphologic and immunophenotypic analysis of fibrofolliculomas and trichodiscomas in Birt-Hogg-Dube syndrome and sporadic disease. J Cutan Pathol 2002;29:529-533.

20. Lindor NM, Hand J, Burch PA, Gibson LE. Birt-Hogg-Dube syndrome: an autosomal dominant disorder with predisposition to cancers of the kidney, fibrofolliculomas, and focal cutaneous mucinosis. Int J Dermatol 2001;40:653-656.
21. Kawasaki H, Sawamura D, Nakazawa H, Hattori N, Goto M, Sato-Matsumura KC, et al. Detection of 1733insC mutations in an Asian family with Birt-Hogg-Dubé syndrome. $\mathrm{Br} J$ Dermatol 2005;152:142-145.

22. Wei MH, Blake PW, Shevchenko J, Toro JR. The folliculin mutation database: an online database of mutations associated with Birt-Hogg-Dubé syndrome. Hum Mutat 2009;30:E880-E890.

23. Gatalica Z, Lilleberg SL, Vranic S, Eyzaguirre E, Orihuela E, Velagaleti $G$. Novel intronic germline FLCN gene mutation in a patient with multiple ipsilateral renal neoplasms. Hum Pathol 2009;40:1813-1819.

24. Lim DH, Rehal PK, Nahorski MS, Macdonald F, Claessens T, Van Geel M, et al. A new locus-specific database (LSDB) for mutations in the folliculin (FLCN) gene. Hum Mutat 2010; 31:E1043-E1051. 